“C 2017 IEEE. Personal use of this material is permitted. Permission from IEEE must be obtained for all other uses, in any current or future media, including reprinting/republishing this material for advertising or promotional purposes, creating new collective works, for resale or redistribution to servers or lists, or reuse of any copyrighted component of this work in other works." 


\title{
Social media adoption framework for aged care service providers in Australia
}

\author{
Babak Abedin*, Shadi Erfani*, Yvette Blount** \\ *Faculty of Engineering \& IT, University of Technology Sydney, Babak.Abedin@uts.edu.au \\ ** Faculty of Business \& Economy, Macquarie University
}

\begin{abstract}
The aged care sector has been a late adopter of social media platforms for communicating, collaborating, marketing and creating brand awareness, and particularly there is little research that examines the adoption of social media by aged care service providers for these purposes. This research is to review the status of social media adoption in the Australian aged care industry, to understand in what ways social media can serve older people's needs, and to develop recommendations for aged-care service providers to adopt social media applications to empower older people. Through review of the literature and interviews with Australian experts, this research provides a three-phase framework. The first phase is to adopt major public social media platforms, Facebook followed by Instagram and Twitter. The second phase should encourage posts and feedback by locally hosted member forums. The third phase should include specialised social applications for closed groups and specific functions. The paper finally discusses implications of the proposed guidelines and proposes directions for future research
\end{abstract} people

Keywords-social media adoption, aged care services, older

\section{INTRODUCTION}

The aged care sector has been a late adopter of social media platforms for communicating, collaborating, marketing and creating brand awareness [1,2]. Social media has been used by organizations more traditionally to engage younger users with the assumption that users have a good level of digital and social media literacy. There is little research that examines the adoption of social media in the aged care sector including the level of digital and social media literacy for older users [3].

The aged-care sector in the Australian region, as well as other places in the world, is dealing with governments' reforms and budget cuts that have changed the focus of aged care services from one of welfare to a market-based approach[4,5]. At 30 June 2016, there were 949 approved providers of residential aged care. During 2015/2016, the Australian Government expenditure on aged care was $\$$ A16.2 billion, an increase of 6.6 percent from the previous year[5]. Aged care providers are increasing their footprint by building scale, depth, and breadth. More importantly, the fastest growing organizations in the last three years have focused on enabling technology and the customer experience including personalization of care [6].

This research investigates the adoption of social media strategies for organizations in the aged care sector. Social media is an enabling platform that can be used to connect older people and their carers and improve the customer experience. This study reports the findings of our recent project with a leading aged care service provider in Australia on how social media may enable aged care service providers to provide competitive and sustainable service and informative content to its existing and future clients as well as the public. The objective of this research was (i) to review the status of social media adoption in the Australian aged care industry, (ii) to understand in what ways social media can serve older people's needs, and (iii) to develop recommendations for aged-care service providers to adopt social media applications to empower older people. To achieve these objectives, we have firstly reviewed existing best practices of social media adoption by aged-care and nonprofit organizations, and secondly conducted interviews with experts in the field to understand how social media may help aged-care service providers and their clients. Next, we synthesized the findings and developed a framework of recommendations for social media adoption by aged care organizations.

\section{RESEARCH BACKGROUND}

There is little research on how and why older people use technology and social media, why they start to use social media , a group of Internet based applications that build on the ideological and technological Foundations of Web 2.0 that allow the creation and exchange of User Generated Content, and why they discontinue.[1,2].

A longitudinal study that examined the reasons older people started using the internet and the reasons why they stopped in Sweden and the Netherlands found that the main reason that older people stopped using the internet was that of compromised cognitive functioning[7]. The existing studies show that internet services are underutilized by older people. However, the use of internet services improves social connection and knowledge capital, which in turn enhances users perceived well-being and health, if the right equipment, support, and advice are provided to them [8].

Research shows an increase in the number of older adults using technology and accessing the internet in developed countries. In a telephone survey of internet use by older people, the most common reasons for using the internet were seeking information, sending and receiving e-mails, online shopping, travel reservations, work-related purposes, online banking and reading newspapers, magazines or books. Over one-third of respondents had taught themselves to use the Internet, a quarter had learned through their respective employment, $25 \%$ had learned via a friend or relative, and a small number had attended a class [3]. Technologies used to alleviate loneliness, and social isolation includes robotics, telecare, 3D environments, video games, chat rooms and social 
media [9]. In rural and remote communities, older people must rely on the internet to access health, financial, education and social services information [10]. Researchers found that mobile phones and personal computers with internet access were the most popular digital devices of older adults aged between 65 and 100 years [10].

In Australia, over 3.6 million of people are aged 65 and over. While in 2011 about $65 \%$ of the older people have accessed the internet at some point in their lives, it was significantly increased to $79 \%$ in 2015 for users who spent an average of seven hours per week (comparing to 9.9 hours for users aged 15 to 65). This shows a considerable interest among this group of users to get online and use digital technologies [11]. Australians aged 65 and over engage in a variety of online activities, with email and banking/bill transactions being the most common activities. In Australia, the number of 65+ men using internet services is higher than women by about $10 \%$. In 2015 most of these users accessed the Internet from home; $68 \%$ used a home desktop, or laptop computer and only $12 \%$ used mobile phones to access digital services [12].

Australian Bureau of Statistics (ABS, 2017) data showed that $43 \%$ of $65+$ Australian internet users engaged with social media in 2015. Facebook, with $88 \%$ of users, is the most popular social platform. Instagram and Twitter with $2 \%$ and $4 \%$ were among the least popular platforms. In 2015, about 500,000 Australian 65+ users used communication tools to send and receive video, text, and photo messages to friends and family members. Furthermore, older Australians are increasingly using social communication tools such as Skype, Facebook Messenger, FaceTime, or Apple iMessenger

\section{A. Social Media/Digital Technology Uptake by Non- Profit and Aged-Care Organizations}

The use of social media can facilitate communication, information distribution and sharing of knowledge that can enhance collaboration and increase productivity. Social media can provide continuous feedback, providing an avenue for stakeholders to influence organizations. Using diverse portfolio social media channels can produce financial and nonfinancial benefits for non-profit organizations [13]. Financial benefits include lower costs, reduced time for communication and fundraising opportunities. Social media is less expensive than traditional media such as billboards, television, and radio that provide non-profit organizations a way to participate in marketing their services and programs to a new, larger, and younger audience of potential donors and clients. Applications such as Go Fund Me and Crowd Rise allow organizations to reach a vast network of potential individual donors and offer an online platform for easily donating directly to causes and organizations [14].

Non-financial benefits include access to a larger audience, an increase in productivity of managers and professionals, provision of continuous feedback channels, and increased web presence [13]. Non-profit organizations use social media to streamline their management functions, distribute organizational news, interact with volunteers and donors, develop relationships with stakeholders and educate others about their programs and services [14].The digital platforms

Identify applicable sponsor/s here. If no sponsors, delete this text box (sponsors). used by non-profits include e-mail, social networks, video sharing, blogs, instant messaging, photo sharing, text messaging, and wikis [15].

Public health agencies use social media to enhance their traditional messaging and provide a mechanism for the elderly to be reminded about medications, to connect with distant family members and to establish new communities around their health care needs[16].In the aged care industry, social media adoption by service providers is still in its early stages. For example, in Australia, while most of the major aged-care service providers have a presence on common social media platforms such as Facebook, Twitter, and LinkedIn, the number of their social media followers, as well as the level of activities on these platforms, is low but increasing.

\section{Older People Motivation to Use or Not Use Social}

It is important to understand how and why older people use or do not use social media. In a research project, respondents were asked why they did not want to learn how to use the internet. Results showed that nearly half reported a lack of interest, others reported time and/or insufficient technical skills [3]. Only a small number (4\%) reported concerns about online security including identity theft. Four percent did not have computer access, and 3\% thought that the Internet was too expensive [17].

A research study found that the digital divide in a case study of a rural town in Australia was not a result of unequal access to technology or socio-economic disadvantage [18]. It was the inability of service providers to adapt their online engagement strategies to the specific needs of older people. Research in rural parts of Australia, the US, and Canada, has shown substantial disadvantage accessing the internet by communities with larger proportions of minorities, such as people from different migrant and language backgrounds or Indigenous people [10]. This finding is supported by other studies [3] that showed that one component of the digital divide, access, and ownership of technology, is not a major issue. However, the second component of the digital divide, the skills, and experience to use the technology, has the potential to exclude access by older people.

Another study found that for adults over the age of 50, staying in touch with family is the number one reason they use social networking sites. For adults under age 50, staying in touch with friends is a bigger motivation [18]. A research study that developed a research model to examine the motivation of older people in adopting social media used three main needs of older adults: health needs, social needs, and dignity needs [19] linked to Maslow's model of the hierarchy of needs. The authors argue that a person that is highly motivated to improve their quality of life, including independence, is more likely to adopt social media. The person is more likely to adopt social media if they have social influences, for example, family and friends that will help them learn what to do. Technical competence, ease of use and the perceived benefits are other factors that are likely to influence adoption of social media.

On the other hand, there are privacy concerns that need to be addressed as well as issues around functional use. For example, as people become older they may have sensory 
impairments (hearing, speech) or cognitive impairments that may limit their ability to adopt social media [1]. To engage older people, it is important to link online social network engagement with topics of personal relevance, such as hobbies, and interests. Researchers have found that older people with higher levels of education and income do not find the barriers to social media problematic. However, as people age, barriers become more noticeable[20].In addition to having proficiency in using the technology to access the internet, using social media needs additional skills. Older people need web skills and an understanding of concepts such as server, search engine, browser as well as an understanding of where and how their personal data is stored and used [20].

\section{RESEARCH DESIGN}

The data for answering the research questions was collected and analyzed in two steps. First, the literature was reviewed, and a benchmark study was conducted to extract lessons learned from adoption social media by leading non-profit and aged-care organizations. We explored nine short cases in this paper, three of which are nonprofit organizations, and six are aged-care service providers. Second, semi-structured interviews were conducted with five experts in the aged-care industry for discovering the ways that social media may empower older people and the challenges they may face in using social media applications.

Thematic analysis, the process of collecting candidate themes and creating relationships between these themes, was used to identify, analyze, and report themes found in the interview transcripts. We analyzed the transcribed interview data using NVivo 8, a software that facilitates the coding and sorting process. Interview responses were coded in six phases: familiarization with the data, generating initial codes, searching for themes, reviewing themes, defining and naming themes, and producing the final reports [21].First, each transcript wasuploaded to NVivo and read several times, to obtain a sense of the entireinterview. The interview text was divided into content areas basedon theoretical assumptions derived from the literature. Within eachcontent area, the text was divided into meaning units. The condensedmeaning units were abstracted and labelled with a code. The variouscodes were compared and sorted into nodes in NVivo.

\section{A. The Benchmarking Study}

Since the adoption of social media by aged-care service providers is in its early stages, we explored best practices of social media adoption both in the aged care sector as well as in the nonprofit sector to broaden our benchmarking study. This ensured that key lessons learned from the aged care sector as well as relevant non-profit sectors were included in our analysis.

\section{Non-Profit Organizations Cases}

In this section, we review social media adoption by three non-profit organizations: Planned Parenthood Federation of America (PPFA), Ovarian Cancer Australia (OCA), and Oxfam Australia:
- $\quad$ PPFA is a trusted health care provider, an informed educator, a passionate advocate, and a global partner helping similar organizations around the world and considered to be one of the most successful NPOs at leveraging social media campaigns to achieve mission goals and influence public behavior [22]. Planned Parenthood delivers vital reproductive health care, sex education, and information to millions of women, men, and young people worldwide. For nearly 100 years, Planned Parenthood has promoted a commonsense approach to women's health, and well-being, based on respect for each's right to make informed, independent decisions about health, sex, and family planning. PPFA health care provider and an advocacy group are one of the most successful NPOs at using social media to influence public behavior [22]. PPFA's posts on Facebook and Twitter often generate more than 10,000 comments and shares in a single day. PPFA's social media campaigns such as Get Yourself Tested (GYT), Real Life, Real Talk have had a positive impact on health practices by reducing the stigma of sexual health, enhancing sexual health behaviors and conversations and improving public policy to be more supportive of health care for women and families. PPFA uses the following approach to manage social media: (i) A team is formed and trained on strategy and outcomes, (ii) a process is in place to continuously assesses social networks (iii) there is a focus on the use visual aids and emotionally appealing stories, to facilitate national conversations and public interest(iv) multiple channels are used to disseminate consistent messages that are contextually relevant to their audience (v) the use of multidirectional flows of information to generate a sense of urgency that translates to stable relationships, and converts viewers into donors and advocates [13].

- The OCA Facebook provides cancer patients with support, offers authoritative cancer-related information, promotes cancer awareness events, and suggests positive behaviors to stay healthy while living with cancer. The use of Facebook had positive impacts on users, for example, users felt that they could obtain more social support, experience social connectedness, develop social presence and learn healthy behaviors and ultimately experience better psychological wellbeing [23]. This example shows that Facebook should be interactive. Suggestions listing current volunteer opportunities, providing an organizational phone number, providing a calendar of events, and providing an e-commerce store on their profile as well as external links to news stories, photographs, and discussion board posts.

- Oxfam implemented social media to increase awareness of their work, promote active citizenship and increase online donations. Engagement with social media helped Oxfam learn what their supporters were saying and sharing about their organization, help drive traffic to websites and blogs, empower supporters to promote the organization, acquire new contacts and build their supporter base and increase trust and loyalty by allowing supporters and stakeholders to share their voice through feedback forums. Social media has helped Oxfam to increase revenue, increase brand awareness, increase website traffic and search rankings, and increased engagement with their target market. Oxfam's social media policy covers the following criteria: (i) Who's 
responsible? Who contributes? What level of access and accountability do different departments or key figures across the organization have? (ii) Rationale: Why are we investing in each platform that we've chosen to be on? If we're ignoring a major platform, why? If we're investing in a smaller, less wellknown platform, what's our logic for doing so? (iii) Identity: What is our brand voice on social media, and how does it relate to our existing brand identity? What is our approach to usergenerated content and community moderation? What relationship are we seeking to build with our followers -- why are we here?

\section{B. Aged Care Service Providers Best Practices}

There are several websites and social media options for older Australians that have adopted the components of communication, information sharing, knowledge sharing and relationship building. The following section discusses active sites that can provide insights into an aged care provider's social media policy.

Table 1 shows that followers of websites and social media specifically targeted at older Australians are significant. People are using social media to stay connected with each other, and current issues as well as find information and resources. As the population ages, there will be more demand for ways to obtain information, form connections with others and express opinions about issues important to them.

TABLE 1 Example of active social media platforms for older Australians

\begin{tabular}{|c|c|c|c|}
\hline Websites /social media & Description & $\begin{array}{l}\text { Facebook } \\
\text { Followers }\end{array}$ & $\begin{array}{c}\text { Twitter } \\
\text { Followers }\end{array}$ \\
\hline $\begin{array}{l}\text { Starts at } 60- \\
\text { https://startsat6o.com/ } \\
\text { START \$ } 60\end{array}$ & $\begin{array}{l}\text { It is for seniors and over 6os in Australia and New } \\
\text { Zealand and was founded in } 2012 . \\
\text { The site covers news, travel, living, romance, gray } \\
\text { nomads, health, money matters, retirement and } \\
\text { retirement lifestyles, hobbies, humor } \\
\text { It is accessed through Facebook, Twitter, and email. }\end{array}$ & $\begin{array}{l}472,782 \\
\text { (Accessed } \\
4.12 .16)\end{array}$ & $\begin{array}{l}1,461 \\
\text { (Accessed } \\
4.12 .16 \text { ) }\end{array}$ \\
\hline \begin{tabular}{ll}
\multicolumn{2}{l}{ Over 6o sixty-Website } \\
$\begin{array}{ll}\text { http:// } \\
\text { OVER6OSIXTY } \\
\text { www.ov } \\
\text { ersixty.c }\end{array}$ \\
$\begin{array}{ll}\text { om.au/ } & \end{array}$
\end{tabular} & $\begin{array}{l}\text { Over6o covers a broad range of topics with content } \\
\text { and articles that are relevant to over-6os. They } \\
\text { encourage contributions by members. There is a } \\
\text { Facebook page, a newsletter, offers for members (e.g. } \\
\text { travel, theater tickets, wine) and an Over6o Catch-ups } \\
\text { where members can create and promote events (e.g. } \\
\text { social events such as bushwalking and walks). }\end{array}$ & $\begin{array}{l}372,165 \\
\text { (Accessed } \\
4.12 .16)\end{array}$ & $\begin{array}{l}, 370 \\
\text { (Accessed } \\
4.12 .16)\end{array}$ \\
\hline $\begin{array}{l}\text { Wyza-Website } \\
\text { WNZA } \\
\text { https://www.wyza.com.au }\end{array}$ & $\begin{array}{l}\text { The website includes news articles, travel, insurance, } \\
\text { lifestyle, entertainment, health, money, property, } \\
\text { deals, and puzzles. Wyza has a presence on Facebook, } \\
\text { Instagram, Twitter, a newsletter and the website. }\end{array}$ & $\begin{array}{l}23,558 \\
\text { (Accessed } \\
4.12 .16)\end{array}$ & $\begin{array}{l}265 \\
\text { (Accessed } \\
4.12 .16)\end{array}$ \\
\hline $\begin{array}{l}\text { National Seniors } \\
\text { Australia- a consumer } \\
\text { lobby group } \\
\text { National Seniors } \\
\text { Australia } \\
\text { http://www.nationalsenio } \\
\text { rs.com.au }\end{array}$ & $\begin{array}{l}\text { There are over } 200,000 \text { members, } 140 \text { branches, and } \\
70 \text { employees and claims to be the fourth-largest } \\
\text { organization of its type in the world. Membership of } \\
\text { National Seniors starts from } \$ 40 \text { for a one-year single } \\
\text { member and } \$ 50 \text { for a one-year joint membership. }\end{array}$ & $\begin{array}{l}7,049 \\
\text { (Accessed } \\
4.12 .16)\end{array}$ & $\begin{array}{l}2,841 \\
\text { (Accessed } \\
4.12 .16)\end{array}$ \\
\hline $\begin{array}{l}\text { Australian Aging Agenda- } \\
\text { bi-monthly magazine and } \\
\text { news website } \\
\text { http://www.australianagei } \\
\text { ngagenda.com.au }\end{array}$ & $\begin{array}{l}\text { For people who work in or around the broad aged } \\
\text { services and retirement living sectors in Australia. } \\
\text { It provides a range of objective news, analysis and } \\
\text { opinion on aging issues and policy, aged care and } \\
\text { seniors housing. }\end{array}$ & $\begin{array}{l}2,352 \\
\text { (Accessed } \\
4.12 .16)\end{array}$ & $\begin{array}{l}, 351 \\
\text { (Accessed } \\
4.12 .16)\end{array}$ \\
\hline $\begin{array}{l}\text { Seniornet-website } \\
\text { SeniarNet } \\
\text { https://www.seniornet.or } \\
\text { g }\end{array}$ & $\begin{array}{l}\text { To provide education for older adults and access to } \\
\text { computer technologies to enhance their lives and } \\
\text { enable them to share their knowledge and wisdom. } \\
\text { Currently in the US and some other countries. }\end{array}$ & $\begin{array}{l}806 \\
\text { (Accessed } \\
4.12 .16)\end{array}$ & $\begin{array}{l}604 \\
\text { (Accessed } \\
4.12 .16)\end{array}$ \\
\hline
\end{tabular}




\section{INTERVIEWS}

Five interviews were conducted with Australian experts and researchers in the field of aged care. The main objective of these interviews was to hear from aged care experts about how social media may empower older Australians, what would the benefits of utilizing social media for them, and how an aged care service provider could help their clients to overcome challenges of using social media platforms. Three of the participants were academics from Australian universities with research experience in aged care, one expert was a founder of a social media platform for older people, and one was a registered nurse with extensive experience in aged care.

Six open-ended questions were designed for an interview. The questions were extracted from relevant previous research in the aged care literature (See Appendix). Each interview was recorded, transcribed, and went for about one hour. While the use of social media is increasingly growing among older Australians through helping them to expand their network, stay in touch with friends and family, learn about community events, and get educated about healthy aging, it is not for everyone. One of the experts believed that social media might not be helpful for people with depression or mental health conditions, as being too much exposed to other older people's (happy) social life may worsen some other people's health and wellbeing. She also believes that carers are increasingly using social media to learn more about the reputation of aged care service providers and their facilities as well as to exchange information and support with other caregivers.

Two of the interviewees stressed that an older person's personality and characteristics play a significant role in encouraging or discouraging them from using social media (or digital technologies in general). They argued that if someone enjoys socializing, is physically and mentally capable of staying in touch with the community and family members, they look for any tools, including social media, to expand their network and to stay connected with the community. On the other hand, if someone is not keen to socialize, is happy with their existing network, or physically/mentally is not able to use the computer technology, then social media is not going to be appealing to them. Extracted themes are shown in Figure 1.

FIGURE1. Interview Themes

\begin{tabular}{|c|c|}
\hline $\begin{array}{c}\text { Use of Internet and social } \\
\text { media }\end{array}$ & $\begin{array}{l}\text { - In general, older Australians are increasingly using social media } \\
\text { - Depends on individuals' willingness and characters: (i) Some enjoy } \\
\text { socializing and engaging in community activities: more likely to use } \\
\text { social media. (ii) some are either happy with existing traditional } \\
\text { network, or not interested in digital technologies }\end{array}$ \\
\hline $\begin{array}{l}\text { Impact of social media on } \\
\text { older Australian qualify of } \\
\text { life }\end{array}$ & $\begin{array}{l}\text {-Two distinct impact: (i) helps social people to expand their nework } \\
\text { and connect with family, friend, and community. also helps to learn } \\
\text { more about health aging; (ii) not helpful for people with } \\
\text { depression/stress or unstable mental conditions }\end{array}$ \\
\hline $\begin{array}{c}\text { Impacts of social media on } \\
\text { carers for improving quality } \\
\text { of care }\end{array}$ & $\begin{array}{l}\text {-To exchnage experience and support with other carers, and to learn } \\
\text { from each other } \\
\text {-To educate carers using videos and educational content } \\
\text {-To keep track of their parents' health status. } \\
\text {-To stay in touch with parents }\end{array}$ \\
\hline $\begin{array}{l}\text { Use of social media in } \\
\text { Australian major cities vs. } \\
\text { remote locations }\end{array}$ & $\begin{array}{l}\text { - Generally, Australian older people share more on social media than } \\
\text { people in the US and UK } \\
\text { - People in regional cities have strong local connections, and thus may } \\
\text { use social media differently than people in bogger cities } \\
\text { - If Internet connection is available, location is not a big factor in social } \\
\text { media use }\end{array}$ \\
\hline $\begin{array}{c}\text { Example of aged care } \\
\text { organizations that use social } \\
\text { media }\end{array}$ & $\begin{array}{l}\text {-While there are many websites with information for older } \\
\text { Australians, only few of them are social platforms } \\
\text {-Examples are: www.startatsixty.com.au and www.oversixty.com.au } \\
\text { (with over 400,000 Facebook members, 1400-3000 } \\
\text { Twitter/Instagram followers, ; www.wyza.com.au (with 25,000 } \\
\text { Facebook members) }\end{array}$ \\
\hline $\begin{array}{l}\text { lintervention programs to } \\
\text { support use of social media } \\
\text { by older people }\end{array}$ & $\begin{array}{l}\text {-Educational programs for Whiddon's clients } \\
\text { - Group learning is most effective for older people } \\
\text { - Use of videos and online content for self-study } \\
\text { - Encouragement from family members and peers }\end{array}$ \\
\hline
\end{tabular}

All interview participants also emphasized that aged care service provider organizations should distinguish between older people in retirement villages and those who choose to live independently outside the village or nursing homes. A distinction should also be made between older people with healthy physical and mental capabilities and those with physical or mental disabilities. A social media plan should 
come in different stages/levels, and should separately target a particular group of older people.

Furthermore, experts disclosed that social isolation is a big contributor to the health and wellbeing of older Australians and that social platforms help older people to stay connected with existing networks and provide opportunities to join new communities. They emphasized that Australian older people are relatively more likely than UK and US fellows to share information on social media, and this creates a great opportunity for aged care providers. Educating older people is an essential factor in empowering them, improving the use of social media websites, and helping older people with the problem of social isolation.

And finally, all experts believed that educational programs are a facilitator for empowering older people to use digital technologies such as social media. Professor Lynn Chenoweth recommends 'group learning' for older people, as not only would this would be a social activity for an aged care provider's existing clients, but also this will improve the motivation and will help an older person feel supported when learning how to use the technology.

Based on the above findings, we extracted six key themes that address one interview question. Figure 1 shows the themes extracted from experts' inputs for the adoption of social media by aged care service providers.

\section{DISCUSSION OF FINDINGS AND RECOMMENDATIONS}

The aged care sector has been a late adopter of social media platforms for communicating, collaborating, marketing and creating brand awareness. However, as older people use social media and digital technologies, aged care service providers will need to adopt and use these platforms for communicating with existing and future clients, educate the public about smart and healthy aging and promote their brand and services. Given that there is little research that examines the adoption of social media in the aged care sector including the level of digital and social media literacy for older users, this paper aimed to provide several practical recommendations for adoption of social media by aged care providers and pave the road for future research into this topic.

Based on our findings, we propose a phased-based framework for adoption of social media by aged care providers. A phased approach allows organizations to implement different social media platforms gradually. The phased approach has the following key advantages:

- Giving the aged care service provider time to allocate resources to their social media campaign

- Receive feedback from the community and make necessary adjustments

- Trial different platforms and learn about their capabilities
- Build skills and capabilities to manage social media and digital technologies

- Prepare for potential risks or negative comments from users, and

- Educate existing clients and caregivers for an effective use of social media contents and potentials.

Figure 2 shows our phased approach for adoption of social media by age care service providers. This framework has three phases:

Phase 1, Utilizing Major Public Social Media Platforms: amongst various public social media websites, we recommend starting with Facebook, and later move to Instagram and Twitter. We have found these three platforms are the most popular channels with older Australians. These platforms will help aged care providers to create an engaging community for existing and potential clients as well as general public and caregivers. It will help these organizations to promote their brand, spread the word about their events and activities, and engage the public for donations. We recommend Facebook to be used to initiate the stories and use/export the content onto Twitter and Instagram simultaneously.

Phase 2, Locally Hosted Member Forum: While the first phase is open to the public, aged care service providers should create a private space for existing clients and/or registered members. The private space can be hosted on (i) their website through a locally created online forum, and/or on (ii) a private group on Facebook, where membership is only possible through invitation and proper screening. This private space provides an excellent platform (i) for aged care organizations to promote internal matters, health and care information to the existing members, and (ii) allow forum members from various villages to get to communicate with one another, organize events, post advertisements, and engage in social activities. This space can also serve as a medium to promote educational programs, videos, and activities to help existing clients to uplift their computer and digital skills.

Phase 3, Specialized Social Applications: specialized social and mobile applications for older people are still in their early stages, and currently we did not find any existing platform with a large user-base for older people. However, we recommend aged care organizations to consider adopting applications such as YourLink.com.au to allow their existing clients to create a customizable space for socializing, meeting new people, and organizing activities. New specialized social applications may emerge in the marketplace soon, and therefore it is recommended to review existing applications at the time of adoption and make a decision based on each applications' features, user-base, and popularity among older users.

\section{FIGURE 2. Phased Social Media Strategy for Aged Care Service Providers}




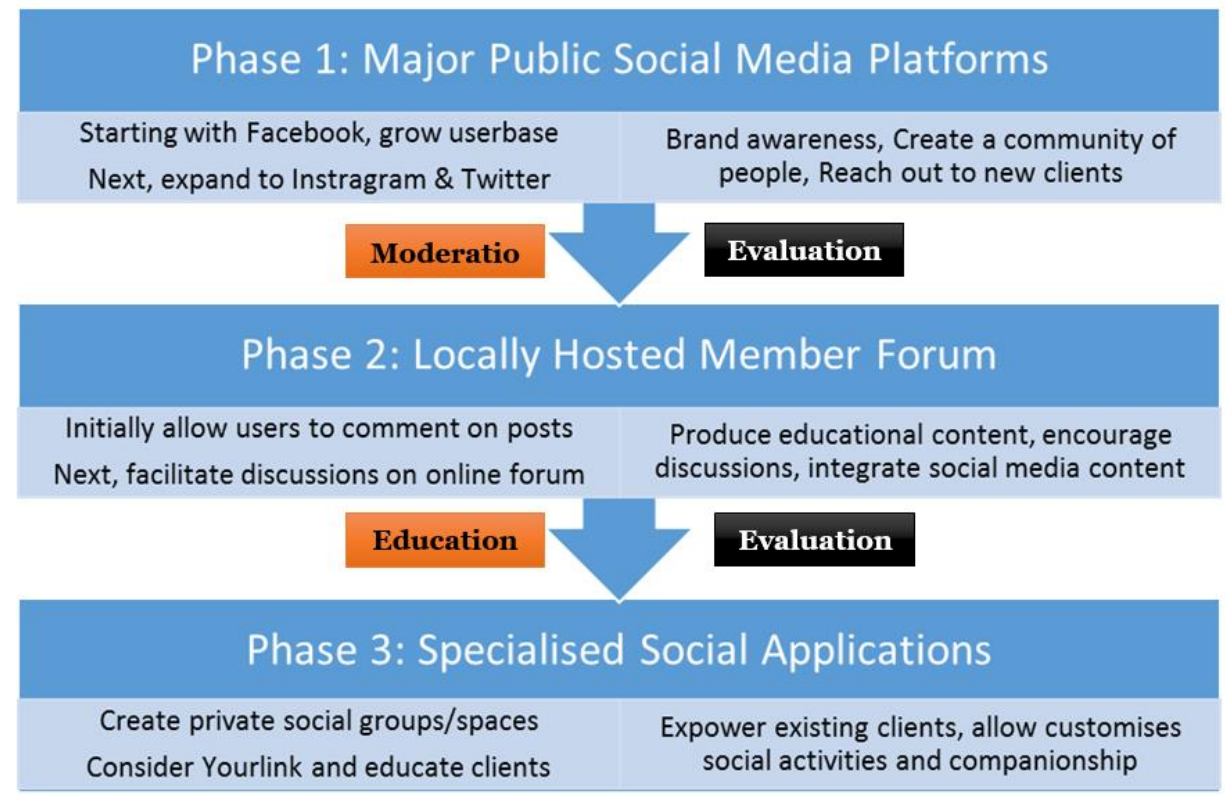

\section{CONCLUSION AND FUTURE WORK}

The research shows that as people age, social media will be important for disseminating information, keeping social connections and staying engaged. Social connections are important for physical and mental health and therefore healthy aging. Supporting healthy aging is a goal for governments around the world because the alternative has implications for the aged care and health care budgets. In the context of Australia, the budget for aged care is increasing; there are many aged care providers in the market making it more competitive and people are demanding more information and transparency to make choices about their health as they age, including their choice of aged care providers.

Future research will include a case study to test the adoption of a phased social media strategy empirically. The authors will investigate several aged care providers in the Australian context on social media strategies and adoption. The intent is to develop a model that will inform aged care providers on best practice social media strategy.

Another area of research will be to investigate social media strategies for aged care providers in the Asia Pacific region. The Ageing Asia Alliance (the Alliance)1, formed in 2012, was set up as Asia Pacific's first industry network on the business of aging. The Alliance has around 1,700 members. The Alliance has an objective to improve the quality of elder care in the Asia Pacific region. We suggest that social media strategies to engage older people should be included in the development of policies across the Asia Pacific Region.

\footnotetext{
${ }^{1}$ See http://www.ageingasia.com/index.php/strategicpartnership/ageing-asia-alliance
}

\section{VIII.APPENDIX: INTERVIEW QUESTIONS}

Question 1: How older Australians are using the Internet to support active aging

Question 2: Does social media enhance or detract from older Australian qualify of life? How?

Question 3: How social media can empower older Australian's carers for improving the quality of care?

Question 4: Does older Australian in major cities and remote locations have different digital literacy? If so, how would this impact their ability to use social media?

Question 5: Are you aware of organizations that use social media to engage and support older Australian? If so, can you please provide details of that

Question 6: What pre-requisite programs/interventions are needed to support older people to use digital and social media platforms?

\section{REFERENCES}

[1] M. T. Braun, 2013. "Obstacles to Social Networking Website Use among Older Adults," Computers in Human Behavior (29:3), pp. 673-680.

[2] D. Deevey, 2016. "Social Media and Health Communication for Seniors." Royal Roads University.

[3] H. R., Marston, M., Kroll, D., Fink, , H., De Rosario and Y. J. Gschwind, 2016. "Technology Use, Adoption and Behavior in Older Adults: Results from the Istoppfalls Project," Educational Gerontology (42:6), pp. 371-387 
[4]Australian Aged Care Quality Agency. 2016. "Australian Aged Care Quality Agency Corporate Plan 201620."

[5] Australian Government Department of Health. 2016. "2015-16 Report on the Operation of the Aged Care Act 1997." $\quad$ Retrieved 23 January 2017, from https://agedcare.health.gov.au/sites/g/files/net1426/f/document s/12_2016/2015-16_report-on-the-operation-of-the-aged-careact-1997.pdf

[6] L. F. N. D. R. Zubrik, (n.d.). "Consumer Directed Care reforms: Navigating the competitive aged care landscape," Consumer Directed Care: Competitive aged care landscape | KPMG | AU (available at https://home.kpmg.com/au/en/home/insights/2016/05/consume r-directed-care-reform-competitive-aged-care-landscape.html; retrieved January 17, 2017).

[7] J., Berner, M., Aartsen, M., Wahlberg, S., Elmståhl, J., Berglund, P., Anderberg, and Deeg, D. 2016. "A CrossNational and Longitudinal Study on Predictors in Starting and Stopping Internet Use (2001-2013) by Swedish and Dutch Older Adults 66 Years and Above," Gerontechnology (14:3), pp. 157-168.

[8] G., Hugo, H., Feist, and G. Tan, 2006. "Australian Population \& Migration Research Centre Policy Brief," Population (2011).

[9] P., Khosravi, A., Rezvani, and A. Wiewiora, 2016. "The Impact of Technology on Older Adults' Social Isolation," Computers in Human Behavior (63), pp. 594-603.

[10] H., Hodge, D., Carson, D., Carson, L., Newman, and J. Garrett, 2016. "Using Internet Technologies in Rural Communities to Access Services: The Views of Older People and Service Providers," Journal of Rural Studies.

[11] Erfani, S. S., Blount, Y., \& Abedin, B. 2016. "The influence of health-specific social network site use on the psychological well-being of cancer-affected people". Journal of the American Medical Informatics Association, 23(3), 467476.

[12] R. L., Briones, B., Kuch, B. F., Liu, and Y. Jin, 2011. "Keeping up with the Digital Age: How the American Red Cross Uses Social Media to Build Relationships," Public relations review (37:1), pp. 37-43.

[13] M. Appleby 2016. "Nonprofit Organizations and the Utilization of Social Media: Maximizing and Measuring Return of Investment," SPNHA Review (12:1), p. 4.

[14] R. D., Waters, E., Burnett, A., Lamm, and J. Lucas. 2009. "Engaging Stakeholders through Social Networking: How Nonprofit Organizations Are Using Facebook," Public relations review (35:2), pp. 102-106.

[15] L., Curtis, C., Edwards, K. L., Fraser, S., Gudelsky, J., Holmquist, K., Thornton, and K. D. Sweetser, 2010. "Adoption of Social Media for Public Relations by Nonprofit Organizations," Public Relations Review (36:1), pp. 90-92.
[16] W. B., Lober, and J. L. Flowers, 2011. "Consumer Empowerment in Health Care Amid the Internet and Social Media," Seminars in oncology nursing: Elsevier, pp. 169-182.

[17] T. Keenan, 2009. "Internet Use among Midlife and Older Adults: An Aarp Bulletin Poll," Washington, DC: AARP).

[18] K., Zickuhr, and M. Madden, 2012. "Older Adults and Internet Use," Pew Internet \& American Life Project (6).

[19] Y., Yang, Y., Yuan, N., Archer, and E. Ryan, 2016. "Adoption of Social Media and the Quality of Life of Older Adults," 2016 49th Hawaii International Conference on System Sciences (HICSS): IEEE, pp. 3133-3142.

[20] H. B., Vošner, S., Bobek, P., Kokol, and M. J. Krečič, 2016. "Attitudes of Active Older Internet Users Towards Online Social Networking," Computers in Human Behavior (55), pp. 230-241

[21] V, Braun, V. Clarke Using thematic analysis in psychology. Qual Res Psychol.2006;3(2):77-101

[22] B. Sundstrom, 2012. "Integrating Public Relations and Social Marketing a Case Study of Planned Parenthood," Social Marketing Quarterly (18:2), pp. 135-151.

[23] S. S., Erfani, B., Abedin, and Y. Blount, 2016. "Social Support, Social Belongingness, and Psychological Well-Being: Benefits of Online Healthcare Community Membership," 20th Pacific Asia Conference on Information Systems (PACIS 2016).

[24] R., Grieve, M., Indian, K., Witteveen, G. A., Tolan, and J. Marrington, 2013. "Face-to-Face or Facebook: Can Social Connectedness Be Derived Online?," Computers in Human Behavior (29:3)

[25] Y., Barnard, M. D., Bradley, F., Hodgson, and A. D. Lloyd, 2013. "Learning to Use New Technologies by Older Adults: Perceived Difficulties, Experimentation Behaviour and Usability," Computers in Human Behavior (29:4), pp. 17151724. 